\title{
A multidisciplinary assessment instrument to predict fall risk in hospitalized patients: A prospective matched pair case study
}

\author{
Heather Chung ${ }^{*}$ Aida Coralic \\ Houston Methodist Hospital, Houston, United States
}

Received: July 14, 2015

Accepted: November 26, $2015 \quad$ Online Published: January 20, 2016

DOI: $10.5430 /$ jnep.v6n6p1

URL: http://dx.doi.org/10.5430/jnep.v6n6p1

\begin{abstract}
Objective: To identify fall risk for hospitalized patients utilizing a multidisciplinary assessment tool based on patients' physical, mental, pharmacological, and metabolic data.

Methods: A prospective case-control design comparing 48 patients who fell (incidence group) and 48 patients who did not experience fall (control group), based on patients' age, gender, and hospital unit location. The study was conducted over an 8-month period at a large academic hospital. Setting: The Methodist Hospital, tertiary care academic referral center with 824 operating beds in Houston, TX. Participants: One hundred and twenty patients, sixty patients who fell, and sixty control subjects. Main Outcome Measures: The sensitivity and specificity of variables identified in logistic regression are able to distinguish patients who fell from patients who did not fall.

Results: Logistic regression results identified six variables (2 summary variables and 4 individual variables) that correctly classified patients with $90 \%$ sensitivity (patients who fell) and $90 \%$ specificity (patients who did not fall). The first variable was an 11-item summary variable that included history, weakness or balance problem, altered mental status or confusion, visual impairment, dizziness or vertigo, urinary tract infection or abnormal urinary analysis (UA), diuretics/IV drips, continence, acute renal failure (ARF), antihypertensives and narcotics. The second variable represented the combination of 3 medication classes: neuroleptic, anticonvulsant and antidepressant. The third variable that had a negative impact on fall risk was the presence of a therapeutic anticoagulant. The other 3 significant variables were hypoglycemia, vital sign abnormality, and low hemoglobin.

Conclusions: A multidisciplinary fall-risk assessment tool that screens combinations of physiological, pharmacological and metabolic patient factors improves the probability of correctly distinguishing patients who were more likely to fall from those patients who were less likely to fall.
\end{abstract}

Key Words: Hospital falls, Fall case study, Fall assessment, Medications and fall risk

\section{INTRODUCTION}

Falls are one of the largest incident types reported in the inpatient hospital setting and frequently result in significant injury, including death, extended length of stay, and increased health care cost. ${ }^{[1]}$ Falls are the fifth leading cause of death among older adults and the most common cause of non-fatal injuries and hospital admissions for trauma. ${ }^{[2,3]}$ The Centers for Medicare and Medicaid Services (CMS) reported that 193,566 cases of falls and trauma occurred in hospitals in 2007, and the additional cost associated with falls and trauma was $\$ 33,894$ per hospital stay. CMS has determined that falls within a hospital are preventable and will no longer reim-

*Correspondence: Heather Chung; Email: HChung@ houstonmethodist.org; Address: Houston Methodist Hospital, Houston, United States. 
burse the facility for medical care if such incident results in a fracture, dislocation or intracranial injury to the inpatient. ${ }^{[4]}$

Previous studies have identified risk factors through assessment scales with variables such as recent history of falls, weakness, impaired balance, altered mental status, dizziness, vertigo, hypotension, altered elimination, need for assistance with ambulation, sensory impairment, agitation, and certain medications. ${ }^{[5-13]}$ Although environmental factors can contribute to falls, it was determined that most falls are a result of physiological control, postural instability, or disease processes. $^{[6]}$

Medications to treat depression, cardiovascular disorders, seizures, mental disorders or pain increase the risk of falls. ${ }^{[14,15]}$ Pharmacological combinations such as opiates, which may cause transient hypotension or syncope, and antihypertensive agents may have cumulative side effects and increase the risk for fall. Diuretics and selective serotonin reuptake inhibitors (SSRIs) have been associated with acute hyponatremia, mild cerebral edema, attention deficits, cardiovascular changes, unsteady gait, and fall-related fractures. ${ }^{[16-19]}$ Loop diuretics may cause orthostatic hypotension leading to an increased risk for falls. ${ }^{[20]}$ The use of central nervous system (CNS) active medications that impair neuromuscular function and the level of alertness have been associated with an increased risk of falling. ${ }^{[21]}$ Metabolic disorders, urinary tract infections, and renal failure have also been associated with an increased risk for falls. ${ }^{[22]}$ Elderly patients are more sensitive to narcotic analgesics with CNS adverse effects, including transient periods of confusion, hallucinations, visual impairment, dizziness, drowsiness, impaired memory, and poor balance. ${ }^{[23]}$

While it is clear that there is no single cause of falls, there are few prospective, case-controlled, matched studies to compare multi-factorial influences and multidisciplinary findings. Case-control studies are often used to identify factors that may contribute to a medical condition by comparing subjects who have that condition/disease (the "cases") with patients who do not have the condition/disease but are otherwise similar (the "controls"). ${ }^{[24]}$ To date, there are no published prospective studies that utilize an age and gender case-control method to determine the fall risk associated with the cumulative effect of pharmacological agents and acute metabolic disorders in hospitalized patients.

The purpose of this study was to determine if the combination of physical, cognitive, pharmacologic, physiologic, and metabolic factors could better predict falls in the acute hospital setting. It was hypothesized that a multidisciplinary fall-risk assessment would improve the probability of correctly distinguishing patients who were more likely to fall from those patients who were less likely to fall.

\section{METHODS}

\subsection{Patients and setting}

A prospective case-control study of inpatients who fell was conducted at Houston Methodist Hospital in the Texas Medical Center from December 2009 through August 2010. A fall was defined as a reported or witnessed unplanned loss of balance that resulted in descent to any level lower than the patient. ${ }^{[1]}$ Falls reported for the medicine, cardiology, oncology, neurology, orthopedics, surgery, rehabilitation, and skilled nursing services were included. Due to acuity, cognitive level and study cost constraints data was not collected for patients in the psychiatric, critical care, and obstetric units and Non-English speaking patients.

\subsection{Participants}

For each patient who fell, a control subject was identified, based on the age, gender, hospital unit where the fall occurred, and the approximate time of the fall. Informed consent was obtained in accordance with the approved Institutional Review Board. Patients who fell and their matched control subjects were interviewed within 48 hours of the fall to identify factors which would contribute to fall.

The total of 60 patients who fell and 60 matched subjects were initially enrolled into the study. Two patients did not have matched subjects and therefore were excluded. One patient who fell withdrew and the matched subject was excluded. Of the remaining 116 subjects, four outliers were removed with corresponding matched subjects. Ninety six remaining subjects (48 patients who fell with 48 age, gender, and unit-based matched control subjects) were included in this study (see Figure 1). Patients who fell had a mean age of 61.1 years (standard deviation of 15.83) and control subjects had a mean age of 60.77 years (SD of 14.58) (see Table 1).

\subsection{Data collection}

Bathroom urgency, call button response time, time of fall, staff to patient ratio at the time of the fall, activity preceding or during the fall, lighting, environmental influences, and other factors were discussed during the interview. Additional information for each enrolled subject was obtained through the patient record. These data included: (1) patients' physiological values: blood pressure, heart rate, and temperature using the patient's baseline values as a comparison, (2) pharmacological agents: opiate, narcotic, sedative, hypnotic, benzodiazepine, antihypertensive, antidepressant, antiarrhythmic, anticonvulsant, neuroleptic, hypoglycemic, anticoagulant, laxative, diuretic, and high rate intravenous fluids, (3) metabolic values: sodium, calcium, blood glu- 
cose, hemoglobin, hematocrit, blood urea nitrogen (BUN), and serum creatinine ( $\mathrm{SCr}$ ), (4) patient-centered variables: history of falls, weakness, balance problem, visual impairment, dizziness or vertigo, the nurse's assessment of the patient's mental status, and demographic data, (5) diagnosis, co-morbidities, surgical interventions, (6) the hospital-based fall assessment score. Data were collected by investigators and a trained data collection Registered Nurse. Standardized data collection packets were utilized to ensure consistency and standardization of data collection process.

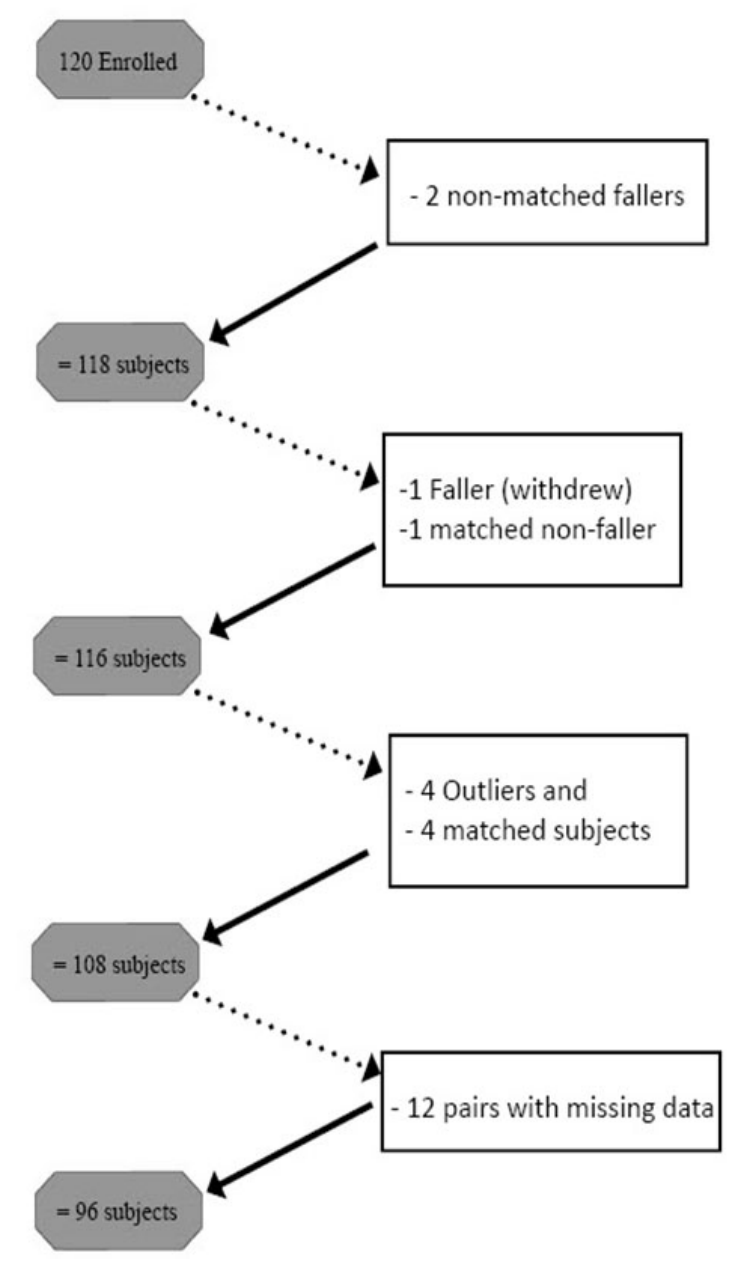

Figure 1. Demographic table and patient medication profile characteristics

\subsection{Data analysis}

IBM SPSS Version 22 software program was used for data analysis. In phase 1, the pharmacological, metabolic, physiological, patient specific variables, interventions, and findings from the post-fall interviews were examined using Chi Square, Fisher's exact, or paired two tailed $t$-tests as appropriate for case-control comparisons. In phase 2 , combination variables were created based on theory, literature review, and evidence-based analysis of the sample. Initial data screening identified a group of eleven variables which significantly distinguished patients who fell from patients who did not fall (see Table 2). The second summary variable comprised three pharmacological agents: neuroleptic, anticonvulsant and antidepressant. In phase 3, logistic regression models were compiled starting with the eleven variable summary score. Additional predictors were added in a stepwise fashion adhering to the 10:1 observation-to-predictor ratio. ${ }^{[25]}$ The results from each model were examined using the Hosmer and Lemeshow goodness of fit, classification tables (specificity and sensitivity), the -2 Log Likelihood of the model (compared to the constrained model), the confidence intervals of the significant predictors, and residual analyses.

\section{RESULTS}

The final logistic regression model with a sample of 96 subjects consisted of six predictors: eleven variable summary score, three drug combination, anticoagulant, abnormal vital signs, blood glucose, and hemoglobin (see Table 2). This model correctly classified $90 \%$ of patients who fell and $90 \%$ patients who did not fall and was statistically reliable in distinguishing between two groups $\left(\chi^{2}(6)=78.29, p<.0001\right)$.

First group of identified fall predictors, named "Eleven variable summary score" that significantly distinguished patients who fell from non-fallers is consisted of: (1) history of falls within the past three months, (2) weakness or balance problem, (3) altered mental status, (4) visual impairment, (5) dizziness or vertigo, (6) urinary tract infection or abnormal urinary analysis, (7) diuretic or intravenous drip, (8) continent, (9) acute renal failure, (10) antihypertensives, and (11) narcotics (see Table 3).

Combination of three pharmacological classes (neuroleptics, anticonvulsants and antidepressants) comprise second summary variable: "Three drug combination". The odds ratio of 4.39 for the three drug combination indicates that a patient is 4.39 times more likely to fall if taking one of the following drugs: neuroleptic, anticonvulsant, or antidepressant. If a patient is taking two of the drugs the patient is almost 9 times more likely to fall. If the patient is taking all three drugs the patient is more than 13 times more likely to fall than a patient who is taking none of the three drugs. The negative effect of anticoagulants on falls indicates that patients on this agent are less likely to fall. For "Blood Glucose", the negative coefficient (B) for the continuous values indicates that as blood glucose drops, patients are more likely to fall. For "Abnormal vital signs", patients with one abnormal vital sign (temperature, blood pressure, or heart rate) near the time of fall, when compared to the patient's baseline, were 10 times more likely to fall than those patients without abnormal vital sign. For the interpretation of the influence of 
hemoglobin on the likelihood of falls requires knowledge of 15.8). Hemoglobin was significantly higher in the group of the range in our sample for this continuous variable (3.5 to patients who fell in this study (see Table 2).

Table 1. Demographic table and patient medication profile characteristics

\begin{tabular}{|c|c|c|}
\hline Characteristics & Patients who fell (number of patients) & Patients who did not fall (number of patients) \\
\hline \multicolumn{3}{|l|}{ Age } \\
\hline$<65$ & 27 & 26 \\
\hline $65-74$ & 12 & 16 \\
\hline$>74$ & 9 & 6 \\
\hline \multicolumn{3}{|l|}{ Gender } \\
\hline Female & 26 & 26 \\
\hline Male & 22 & 22 \\
\hline \multicolumn{3}{|l|}{ Education level } \\
\hline Less than college & 3 & 7 \\
\hline High School & 17 & 15 \\
\hline Some college & 7 & 7 \\
\hline Associate Degree & 5 & 6 \\
\hline University Grad & 12 & 8 \\
\hline Post-Graduate & 4 & 5 \\
\hline \multicolumn{3}{|l|}{ Marital Status } \\
\hline Married & 26 & 30 \\
\hline Single & 13 & 6 \\
\hline Widowed & 6 & 6 \\
\hline Divorced & 3 & 6 \\
\hline \multicolumn{3}{|l|}{ Prior $\mathbf{H x}^{*}$} \\
\hline Yes & 24 & 20 \\
\hline No & 23 & 27 \\
\hline Not known & 1 & 1 \\
\hline \multicolumn{3}{|l|}{ Medication } \\
\hline Diuretic/IV fluid** & 24 & 16 \\
\hline Laxative & 10 & 11 \\
\hline Opiate Narcotic & 30 & 23 \\
\hline Sedative/Hypnotic & 8 & 10 \\
\hline Benzodiazepine & 12 & 11 \\
\hline Antihypertensive & 38 & 30 \\
\hline Antiarrhythmic & 48 & 48 \\
\hline Antidepressant & 22 & 17 \\
\hline Neuroleptic & 5 & 6 \\
\hline Anticonvulsant & 14 & 8 \\
\hline Anticoagulant & 10 & 13 \\
\hline Hypoglycemic agent & 23 & 24 \\
\hline
\end{tabular}

*History of falls, CVA, amputation, weakness, balance disorder, neuro-muscular disease; ** IV fluid administered at rates $>40 \mathrm{ml} / \mathrm{hour}$.

Table 2. Logistic regression: Six variable groups that increase the risk of falling

\begin{tabular}{lllllllll}
\hline & B & S.E. & Wald & Df & Sig. & $\begin{array}{l}\text { Odds } \\
\text { Ratio }\end{array}$ & \multicolumn{2}{l}{ 95.0\% C.I. for OR } \\
\cline { 6 - 10 } & & & & & & & Lower & Upper \\
\hline Eleven variable summary score & 2.269 & .535 & 17.990 & 1 & .000 & 9.665 & 3.388 & 27.573 \\
Three drug combination & 1.480 & .524 & 7.994 & 1 & .005 & 4.394 & 1.575 & 12.260 \\
Anticoagulant & -2.539 & .996 & 6.496 & 1 & .011 & .079 & .011 & .556 \\
Blood glucose & -.041 & .012 & 11.289 & 1 & .001 & .960 & .937 & .983 \\
Vital sign & 2.316 & .823 & 7.923 & 1 & .005 & 10.137 & 2.021 & 50.853 \\
Hemoglobin & .846 & .276 & 9.380 & 1 & .002 & 2.330 & 1.356 & 4.005 \\
Constant & -17.232 & 4.766 & 13.075 & 1 & .000 & .000 & \\
\hline
\end{tabular}


Table 3. Eleven variable summary. Four clusters of variables (patient specific, urgency, acute renal failure and pharmacological agents) identified as potential fall risk predictors

\begin{tabular}{|c|c|}
\hline \multicolumn{2}{|c|}{ Eleven Variable Summary } \\
\hline \multirow{5}{*}{ Patient History } & History of Falls \\
\hline & Weakness or Balance Problem \\
\hline & Altered Mental Status \\
\hline & Visual Impairment \\
\hline & Dizzy or Vertigo \\
\hline \multirow{3}{*}{ Urgency } & Abnormal Urine Analysis \\
\hline & Diuretics or IV drip \\
\hline & Continent \\
\hline Kidney Function & Acute Renal Failure \\
\hline \multirow{2}{*}{ Drugs } & Narcotics \\
\hline & Antihypertensive Agents \\
\hline
\end{tabular}

\section{DISCUSSION}

In the hospital setting multiple risk factors can combine to contribute to patient falls and severe injuries. Using logistic regression, a multidisciplinary fall risk prediction assessment guide has been developed for the acute hospital setting that is based on physical, mental, pharmacological, and metabolic patient information. ${ }^{[26,27]}$ The sensitivity (ability to predict patients who will fall) and the specificity (ability to predict patient who will not fall) were each $90 \%$ using six fall risk predictors. The reliability and usability of this novel instrument is being evaluated in ongoing large multi-center fall trial.

The most significant fall predictor was a summary score based on items commonly reported in the literature as contributing to falls, such as a history of falls, weakness, balance problem, dizziness, and visual impairment Narcotics and antihypertensive agents were included in this summary score based on the strength of the association to falls in this sample. It would be valuable to know if narcotics or antihypertensive agents were newly introduced to the patients who fell, as most of the side effects associated with fall risk are present at the initiation of the therapy. Most agents in this class affect basic CNS functions and can cause transient periods of dizziness with balance or visual impairment, in addition to confusion and transient memory loss. ${ }^{[28]}$ Patients with impaired hepatic metabolism and impaired renal elimination may be more sensitive to usual recommended adult doses. To prevent fall events associated with urgency, pharmacological factors should be evaluated along with environmental adjustments. Use of diuretics or vigorous fluid resuscitation may not be avoided most of the time. Interventions that should be considered in these situations are: (a) minimize late evening diuretic administration to prevent nocturnal ur- gency and bathroom visits, (b) provide assistance to toileting 15 to 20 minutes after diuretic administration, (c) minimize duration of aggressive fluid resuscitation, and discontinue as soon as the patient's oral intake becomes adequate.

While the eleven variable summary score was the strongest predictor (correctly identifying $60 \%$ of patients who fell), the inclusion of four additional drugs (anticoagulant, neuroleptic, anticonvulsant, and antidepressant agents) to the prediction model increased the sensitivity to $83 \%$. Patients on anticoagulants in this study were less likely to fall. All patients on warfarin at this institution receive education by a pharmacist regarding safety which probably contributed to the increased patient awareness of the risks and potential harms from falling. This study suggests that close monitoring of patients on a combination of anticonvulsant, antidepressant, and neuroleptic agents should occur.

The presence of several high risk pharmacological factors necessitates strong pharmacy presence and therapy evaluation for hospital fall risk prevention. Nursing staff should be readily available to assist high risk patients to and from the bathroom in a timely manner. Fall prediction in the acute hospital setting was further enhanced through the inclusion of two metabolic factors: hemoglobin and blood glucose. The interpretation of the impact of high hemoglobin in this study has to be made with caution based on the large range of values.

Falls associated with hypoglycemia have been reported in the literature, but the findings from this study suggest the importance of using the patient's baseline blood glucose level as a comparison to monitor drops in blood sugar. The results indicate that for every unit decrease in blood glucose, the patient is .96 times more likely to fall. In clinically relevant terms, this finding can be interpreted to mean that for every 10 point drop in blood glucose from the patient's typical value, the patient is almost 10 times more likely to fall.

\section{Study limitation}

A limitation of this study is that patients in the psychiatric, women's service and intensive care areas were not included. The research team is currently testing the sensitivity and specificity of the developed fall risk assessment instrument, this restricts our ability to include it into this manuscript.

\section{Conclusion}

Prospective case control-study was designed to evaluate hospital fall risks and to develop the new fall risk assessment instrument. The demographic group, hospital setting and fall situations which were used in this study allows for generalizability of this study findings. Since women are at higher risk 
for falls in the acute hospital setting, gender was a factor controlled in the study. Age was controlled in this study due to the fact that patients in the acute setting are not limited to the geriatric population as fall risks have been strongly linked to age. This study suggests that metabolic and pharmacological factors are strong predictors in hospitalized patients and if recognized, early appropriate intervention can be made to decrease falls in hospitalized patients.

Close collaboration with patients is essential in identification of fall risk factors. Upon admission to the hospital providers of the health care team should evaluate patients' perceptions regarding their history of falling, risk of falling and willingness to comply with interventions to prevent falls. Approaches that promote behavior modification and compliance include patient education and providing patients with information on how to prevent falls. Interventions should be individualized with the focus on maintenance of patients' independence under maximal safety. Critically important professional disciplines in multidisciplinary team include physical therapist who provide expertise in patients gait and balance assessment, as well as clinical pharmacist who review medication profiles for possible side effects that can increase risk for falls. Nurses and nursing assistants play a major role in patients' fall safety by being proactive in assisting patients to the toilet, promptly answering patients' calls, keeping supplies within reach, and vital signs monitoring.

Since the risk of falling increases with the number of risk factors, risk can be minimized by interventions that will eliminate or minimize factors that can increase falls. The large multi-center fall prevention study is currently investigating validity and practicality of the fall prevention instrument built on the risk variables identified in this study. Results of this research will be critical in the future use of this tool in minimizing fall risk factors.

\section{ACKNOWLEDGEMENTS}

The work was funded by The Methodist Hospital Research Institute.

\section{CONFlicts of InTERest Disclosure}

The authors declare that there is no conflict of interest.

\section{REFERENCES}

[1] Morse JM. Preventing patient falls. (2nd ed). New York: NY: Spring Publishing Company; 2009.

[2] Centers for Disease Control and Prevention. Injury prevention \& control: Home and recreational safety. 2011. Available from: http://www.cdc.gov/HomeandRecreationalSafety/ Falls/index.html

[3] Stevens JA, Corosco PS, Findelstein EA, et al. The cost of fatal and non-fatal falls among older adults. Inj Prev. 2006; 12(5): 290295. PMid:17018668 http://dx.doi.org/10.1136/ip. 2005.0 11015

[4] Centers for Medicare \& Medicaid Services. 2008. Available from: http://edocket.access.gpo.gov/2008/pdf/08

[5] Morse JM, Morse RM, Tylko SJ. Development of a scale to identify the fall prone patients. Canadian Journal on Aging. 1989; 8: 366-77. http://dx.doi.org/10.1017/S0714980800008576

[6] Hendrich A, Nyhuuis A, Kippenbrock T, et al. Hospital falls: Development of a predictive model for clinical practice. Applied Nursing Research. 1995; 8: 129-139. http://dx.doi.org/10.1016/S08 97-1897 (95) 80592-3

[7] Schmid NA. Reducing patient falls: A research-based comprehensive fall prevention. Military Medicine. 1990; 155(5): 202-2007. PMid:2114579

[8] Smith J, Foster A, Young J. Use of the "STRATIFY" falls risk assessment in patients recovering from acute stroke. Age and Ageing. 2006; 35: 138-143. PMid:16368736 http://dx.doi .org/10.10 93/ageing/afj027

[9] Ganz A, Yeran B, Shelelle P, et al. Why my patients fall? Journal of the American Medical Association. 2007; 297(1): 7786. PMid:17200478 http://dx.doi.org/10.1001/jama. 297. 1.77
[10] Stalenhoef PA, Diederiks JP, Knottnerus JA, et al. A risk model for the prediction of recurrent falls in community-dwelling elderly: a prospective cohort study. Journal of Clinical Epidemiology. 2002; 55(11): 1088-1094. http://dx.doi.org/10.1016/S0895-435 6(02) 00502-4

[11] Delbaere K, Close JC, Heim J, et al. A multifactorial approach to understanding fall risk in older people. Journal of the American Geriatrics Society. 2010; 58(9): 1679-1685. PMid:20863327 http://dx.doi.org/10.1111/j.1532-5415.2010.03017.x

[12] Muir SW, Berg K, Chesworth B, et al. Quantifying the magnitude of risk balance impairment on falls in community-dwelling older adults: A systematic review and meta-analysis. Journal of Clinical Epidemiology. 2010; 63(4): 389-406. PMid:19744824 http://dx.doi.org/10.1016/j.jclinepi.2009.06.010

[13] Chung H. The lived experience of older adults who fall during hospitalization. Pro Quest dissertation and thesis database. 2009. 1-103

[14] Lepizig RM, Cumming RG, Tinneti ME. Drugs and falls in older people: a systematic review and meta-analysis. Journal of the American Geriatrics Society. 1999; 47(1): 30-9. http://dx.doi.org/1 $0.1111 / \mathrm{j} .1532-5415.1999 . \mathrm{tb01898} . \mathrm{x}$

[15] Krauss MJ, Evanoff B, Hitcho E, et al. A case-control study of patient, medication, and care-related risk factors for inpatient falls. Journal of General Internal Medicine. 2005; 20: 116-122. PMid:15836543 http://dx.doi.org/10.1111/j.1525-1497.2005.40171.x

[16] Kengne FG, Andres C, Sattar L, et al. Mild hyponatremia and risk of fracture in the ambulatory elderly. Q JM. 2008; 101(7): 583-588. PMid:18477645 http://dx.doi.org/10.1093/qjmed/hcn061

[17] Wilkinson TJ, Begg EJ, Winter AC, et al. Incidence and risk factors for hyponatremia following treatment with fluoxetine or paroxetine in elderly. British Journal of Clinical Pharmacology. 1999; 
47(2): 211-217. http://dx.doi.org/10.1046/j.1365-2125. 1999.00872.x

[18] Spital A. Diuretic-induced hyponatermia. American Journal of Nephrology. 1999; 19(4): 447-452. http://dx.doi.org/10.11 $59 / 000013496$

[19] Carbone LD, Johnson KC, Bush AJ, et al. Loop diuretics and fracture in postmenopausal women. Archives of Internal Medicine. 2009; 169(2): 132-140. PMid:19171809 http://dx.doi .org/10.1001 /archinternmed.2008.526

[20] Poon IO, Braun U. High prevalence of orthostatic hypotension and its correlation with potentially causative medication among elderly veterans. Journal of Clinical Pharmacy and Therapeutics. 2005; 30(2): 173-178. PMid:15811171 http://dx.doi.org/10.1111/j.136 5-2710.2005.00629.x

[21] Ensrud KE, Blackwell TL, Mangione CM, et al. Central nervous system-active medication and risk for falls in older women. Journal of the American Geriatrics Society. 2002; 50(10): 1629-1637. http://dx.doi.org/10.1046/j.1532-5415.2002.50453.x

[22] Renneboog B, Musch W, Vandemergel X, et al. Mild chronic hyponatremia is associated with falls, unsteadiness, and attention deficits. American Journal of Medicine. 2006; 119(1): 71.el-8.
[23] Fick DM, Cooper JW, Wade WE. Updating the beers criteria for potentially inappropriate medication use in older adults. Archives of Internal Medicine. 2003; 163(22): 2716-2724. PMid:14662625 http://dx.doi.org/10.1001/archinte.163.22.2716

[24] Rubenstein LZ. Falls in older people: epidemiology, risk factors and strategies for prevention. Age and Ageing. 2006; 35(S2): ii37-ii41. http://dx.doi.org/10.1093/ageing/af 1084

[25] Hosmer DW, Lemeshow S. Applied Logistic Regression. New York: Wiley; 1989.

[26] Menard S. Applied logistic regression analysis. Sage university paper series on quantitative applications in the social sciences. Thousand Oaks, CA: Sage. Mickelson; 1995.

[27] Anderson RP, Ruyun J, Grunkemeier GL. Understanding logistic regression analysis in clinical reports: an introduction. Annals of Thoracic Surgery. 2003; 75(3): 753-757. http://dx.doi .org/10. 1016/S0003-4975(02) 04683-0

[28] Schor JD, Levkoff SE, Lipsitz LA, et al. Risk factors for delirium in hospitalized elderly. Journal of the American Medical Association. 1992; 267(6): 827-831. http://dx.doi.org/10.1001/jama.19 92.03480060073033 